\title{
Green AgNPs Decorated ZnO Nanocomposites for Dye Degradation and Antimicrobial Applications
}

Pranav Jadhav, ${ }^{1}$ Sujit Shinde, ${ }^{1}$ Suresh S. Suryawanshi, ${ }^{2}$ Shivanand B. Teli, ${ }^{3}$ P.S. Patil, ${ }^{1}$ A. A. Ramteke, ${ }^{4}$ N.G. Hiremath ${ }^{4}$ and Neeraj. R. Prasad ${ }^{1 *}$

\begin{abstract}
Nanotechnology is an ablaze branch for the scientists and deals with the study of synthesis, characterization and application of nanomaterial. Phytochemicals available as bio-molecules present in Gongura leaves can be used to reduce silver ions into silver nanoparticles (AgNPs) in a single step by novel synthetic routes. This biogenic reduction of silver ions to silver metal is quite rapid and can be easily scaled up. ZnO NPs are synthesized using popular hydrothermal route. X-ray diffraction pattern of reaction product confirmed the formation of silver and ZnO NPs. Optical properties, size and morphology of the ZnO-AgNPs composites have been analyzed using advanced characterization techniques. The bare AgNPs are spherical in shape with the particle size ranging from 1.1 to $1.5 \mu \mathrm{m}$ where the ZnO NPs are in nanorods shape with the particle size ranging from 0.3 to $0.4 \mu \mathrm{m}$. The synthesized $\mathrm{ZnO}-\mathrm{Ag}$ composites show a potential biological efficacy against pathogenic micro-organisms and are effective in dye degradation. Both of the antimicrobial and antioxidant activity facilitate the application of nanoparticles in medical and veterinary sciences. The $5 \%$ AgNPs containing ZnO nanocomposites demonstrates a photodegradation of methylene blue (MB) dye $(5.0 \mathrm{~g} / \mathrm{dm} 3)$ with an efficiency up to $99.21 \%$ within 75 min under UV light irradiation. This study gives an excellent dye degradation efficiency.
\end{abstract}

Keywords: Green approach; Silver and zinc oxide nanoparticles; Dye degradation; Antimicrobial activity; Antioxidant. Received: 10 August 2020; Accepted: 21 September 2020.

Article type: Research article.

\section{Introduction}

Nanotechnology explores electrical, optical, and magnetic activity as well as structural properties of material at the molecular and sub-molecular level. It has the potential to inspire a series of medical, veterinary and biotechnology tools. Nanoparticles find a wide range of applications in diverse areas such as Agriculture Science, Animal Husbandry, Biotechnology, Chemical Science, Electronic Engineering, Medical science, Veterinary Science etc. Nanoparticles are being used for different purposes, such as in medical treatments, cancer therapy in hyperthermia, and targeted drug

\footnotetext{
${ }^{1}$ School of Nanoscience and Technology, Shivaji University, Kolhapur - 4160004 (MH), India.

${ }^{2}$ Department of Biochemistry, Shivaji University, Kolhapur-4160004 (MH), India.

${ }^{3}$ Nanomaterial Laboratory, Department of Chemistry, Shivaji University, Kolhapur-4160004 (MH), India.

${ }^{4}$ Deapartment of Chemistry, Devchand College, Arjun Nagar -591237, Taluka Kagal, India.

*E-mail: neeraj_prasad21@ @rediffmail.com (N. Prasad)
}

delivery, gas sensing devices, memristers, metamaterials, electrochromic materials, superhydrophobic materials, electronics, cosmetic industry and biosensors. Apart from these, they also find applications in the fabrication of various advanced devices such as solar cells and oxide fuel batteries for energy storage. ${ }^{[1]}$

Nanoparticles are being used in various sensing devices such as in different types of bio- sensors, various types of gas sensors, electronic taste sensors also known as electronic tongue, supercapacitors, lithium ion batteries, textile materials construction materials such as nanotiles, solar cells, electrochromic materials and fuel cells. Apart from these domains, the application area of nanomaterials has been extended to cosmetic materials and treatment of some cancers due to their exceptional properties such as hyperthermia, high resistance to oxidation and high thermal conductivity. Cosmetics products are used to enhance or alter the look of the face or fragrance of the body. ${ }^{[2]}$ Lots of cosmetics are prepared for being applied to the face, hair, and body. For this purpose, we plan to synthesize cosmetics material by different synthesis routes such as chemical route and biological route. The sun cloths, sunglasses etc. are used to prevent ultraviolet (UV) 
radiation. Some fabrics are specially made to provide sun protection that comes with an UV protection factor. Therefore, nanoparticles have attracted considerable attention of researchers from various disciplines of sciences and technology in recent years. Normally any kind of fine and classicist nanoparticles are produced by employing chemical or biological routes. ${ }^{[3,4]}$

Thus, genuinely the metal-based nanoparticles are widely introduced into some in vivo products such as cosmetics, face creams, ointments, lotions, food packaging and sunscreens because of their ability to absorb UV light or to protect the skin from harmful UV rays. Mostly the transition metals and their oxide composites have an excellent UV absorption efficiency and transparency. ${ }^{[5]}$ The UV rays with a relatively low wavelength i.e. UVB (290-320 nm) radiation have been proven to cause DNA damage both directly and indirectly. Nanosized $\mathrm{ZnO}$ is an excellent photocatalyst, in which free electrons and holes can be generated by light stronger than its bandgap energy. This electron holes pairs diffuse out on the surface and transform the surrounding oxygen and water molecules into hydroxyl and peroxyl radicals via a strong oxidation.

In the development of several kinds of medicinal products, $\mathrm{ZnO}$ nanoparticles are governed due to their disinfecting, antibacterial, and drying properties. ${ }^{[6-10]}$ Cosmetics have been in usage for thousands of years. The synthesis of cosmetic material requires transition metals such as $\mathrm{MgO}, \mathrm{ZnO}, \mathrm{TiO}_{2}$, silver and many other transition metal and metal oxides. $\mathrm{ZnO}$ based nanoparticles are united constituents of personal care products including cosmetics and sunscreens because of strong absorption property of ultraviolet light and high transparency on the skin considering its use for medical and pharmaceutical fields. ${ }^{[1]}$ In case of stability, organic reagents are more unstable than inorganic $\mathrm{ZnO}$ nanoparticles due to vast specific surface area with an excessive photocatalytic activity, in which free electrons and holes can be generated by light stronger than its bandgap energy. Antibacterial agents like antiseptics, antidandruff shampoos, baby powder, and calamine powder contain $\mathrm{ZnO}$ particles. Hydrogen peroxide can be generated and can enter through the cell membrane. This hydrogen peroxide will injure the cell and disallow the development of the cells. ${ }^{[12]}$ The antibacterial property of the $\mathrm{ZnO}$ nanoparticles depends on the concentration, size, healing temperature and affinity between the $\mathrm{ZnO}$ and bacterial cells. ${ }^{[13]}$ These nanoparticles are an ideal potential antibacterial reagent to replace some antibiotic, on account of selective toxicity and are generally considered as a safe reagent to human and animals. ${ }^{[14,15]} \mathrm{ZnO}$ is an essential ingredient of many enzymes, sun screens and ointments for pain and itch relief. The impact of $\mathrm{ZnO}$ on biological function depends upon its morphology and size.

On the other hand, the antibacterial effectiveness are strongly determined by their shape, size, concentration and colloidal state. Silver (Ag) is enormously considered as antibacterial agent, which has been applied to diminish the growth of bacteria, fungi, and viruses. ${ }^{[16]}$ Practically, nitrate form of silver is an active antibacterial agent, but when the Ag NPs are applied as an antibacterial agent, they are more effective than silver nitrate. It occurs due to larger specific surface area and higher surface charge. ${ }^{[17]} \mathrm{Ag}$ NPs act as an antibacterial, antifungal and antiviral agent. When treated with Ag NPs, the binding of NPs on the cell wall leads to morphological changes like shrinkage of the cytoplasm and membrane separation, which direct the damaging of the cell wall. ${ }^{[18-19]}$ Furthermore, AgNPs are more lethal against the gram- negative bacterial species due to the presence of a thinner cell wall and the presence of a small amount of peptidoglycan. Cell membrane of gram-negative bacteria contains lipopolysaccharide layer (LPS), which contributes to the negative changes on the membrane. These LPS particles boost the binding of the AgNPs and make bacteria more sensitive against AgNPs during the mediated antibacterial treatment.

In this research work, an endeavor has been accomplished to study anti-microbial, antioxidant and dye degradation of $\mathrm{ZnO}$ and $\mathrm{Ag}$ framed nanocomposites ( $\mathrm{ZnO}-\mathrm{Ag} \mathrm{NPs}$ ). Minimal inhibitory concentration is investigated. The prospect role of free-radical ions generated around $\mathrm{ZnO}-\mathrm{AgNPs}$ inhibition was measured by 2,2-diphenyl-1-picrylhydrazyl (DPPH) and 2,2'azino-bis(3- ethylbenzothiazoline-6-sulphonic acid (ABTS) activity. It was planned to examine the antimicrobial efficacy of synthesized NPs against Gram-negative bacteria including Escherichia coli, Salmonella typhiand, Pseudomonas aeruginosa and one Gram- positive bacterium Bacillus cereus. The synergetic effectiveness of synthesized NPs was studied with common antibiotics like streptomycin. In order to examine the photocatalytic degradation effect, $10 \mathrm{ppm}$ solution of methylene blue (MB) was used.

\section{Experimental Section}

\subsection{Chemicals and microorganisms}

Zinc acetate $\left(\mathrm{C}_{4} \mathrm{H}_{6} \mathrm{O}_{4} \mathrm{Zn} .2 \mathrm{H}_{2} \mathrm{O}\right)$, silver nitrate $\left(\mathrm{AgNO}_{3}\right)$, sodium hydroxide $(\mathrm{NaOH})$, ammonia and methylene blue dye were procured form Sigma-Aldrich, Milwaukee (USA). DPPH, nutrient agar, streptomycin, ABTS, solvents of HPLC grade and other chemicals were purchased from Himedia, Mumbai, India. The Fresh Gongura (Hibiscus cannabinus) leaves were collected from campus of Shivaji University, Kolhapur, (MH) India (N-16.67.35, E-74.25.32). Different agar plates were prepared in our laboratory using submerged growth of bacterial strains such as Escherichia coli (MNCL2832), Salmonella typhi (MNCL2501), and Pseudomonas aeruginosa (MNCL5032) and Bacillus cereus (MNCL2703), which were obtained from National Chemical Laboratory (NCL) Pune. India. Distilled water was used as negative control and was purified with a (Millipore, USA) water purification system with a resistivity of $18.2 \mathrm{M} \Omega / \mathrm{cm}$.

\subsection{Synthesis of green-Ag nanoparticles (Green-AgNPs)}

Firstly $10 \mathrm{~g}$ fresh Gongura leaves were collected from Shivaji University, Kolhapur campus. ${ }^{[20]}$ The leaves were cleaned in 
running water followed with doubled distilled water and chopped into small pieces. Then the chopped pieces of leaves were taken in a beaker containing $50 \mathrm{~mL}$ of double distilled water. This whole assembly was heated at $60^{\circ} \mathrm{C}$ for about 10 min. Then the decoction was collected in a beaker. This decoction acted as reducing agent and capping agent. The $\mathrm{pH}$ of Gongura extract was adjusted at 13 using $\mathrm{NaOH}$ so as to enhance the ability of bio- molecules. The literature reiew reveals that Gongura leaf extract contains alkaloids, which contains heterogeneous nitrogen atom to donate electrons in a chemical reaction. Then $0.01 \mathrm{M} \mathrm{AgNO}_{3}$ solution was prepared in double distilled water. After this, the prepared fresh solution of $\mathrm{AgNO}_{3}$ was slowly added in Gongura extract. This resulted in the precipitation of silver in the nano form. The precipitated silver was separated using high speed centrifugation machine rotated with $1000 \mathrm{rpm}$. The $\mathrm{pH}$ altered the charges on bimolecular. As temperature was increased, the kinetic energy of molecule was increased and smaller AgNPs with uniform distributions were formed. This revealed that controlled parameters were important for the synthesis of Green- AgNPs. The experimental set up is pictorially represented in Fig. 1. It has been observed that the formation of AgNPs took place within 30 minutes.

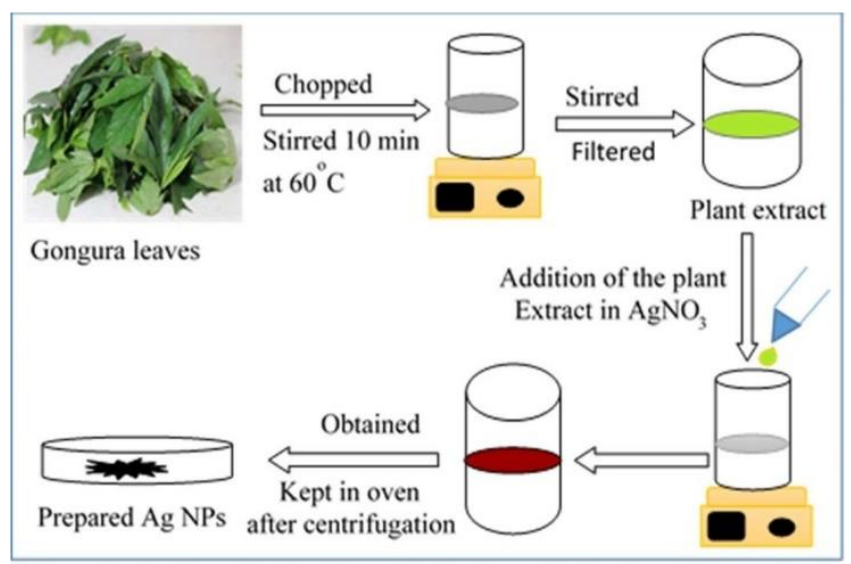

Fig. 1 Schematic representation of synthesis of Green-Ag nanoparticles.

\subsection{Mechanism of biosynthesis of metallic nanoparticles}

The possible reaction mechanism for the NPs synthesis using plants is supposed to be due to the presence of carbonyl groups in aspartic acid and glutamine residues and the hydroxyl residues of proteins. The main mechanism considered for this process is the plant assisted reduction due to phytochemicals. The main phytochemicals involved are terpenoids, flavones, ketones, aldehydes, amides and carboxylic acids. Flavones, organic acids and quinones are water soluble phytochemicals that are responsible for the immediate reduction of the ions. Studies have revealed that xerophytes contain emodin and anthroquinone that undergo tautomerization, leading to the formation of AuNPs. In the case of mesophytes, three types of benzoquinone, namely, cyperquinones, dietchequinone and remirin were noticed. It was suggested that the phytochemicals involved directly in the reduction of ions and the formation of AgNPs. Though the exact mechanism involved in each plant varies as phyto- chemical involved varies, the major mechanism involved is the reduction of ions.

\subsection{Synthesis of $\mathrm{ZnO}$ nanopowder}

Zinc oxide nanoparticles were prepared using zinc acetate precursor. For the current experimentation process, $0.1 \mathrm{M}$ zinc acetate solution was prepared in double distilled water. $50 \mathrm{~mL}$ of aqueous solution was taken in a borosilicate beaker and maintained on magnetic stirrer to make homogeneous and clear solution. Once the solution became homogeneous and clear, ammonia $\left(\mathrm{NH}_{3}\right)$ was taken in borosilicate burette and slowly added dropwise with continuous stirring. After addition of few $\mathrm{mL}$ of ammonia $\left(\mathrm{NH}_{3}\right)$ in solution, initially precipitate was formed. After further addition of ammonia, the solution became colorless. Then resultant reaction mixture was transferred in a stainless still autoclave system and hydrothermally treated at $90^{\circ} \mathrm{C}$ for one hour. After completion of reaction, the resultant system was allowed to cool down to room temperature. Then the synthesized powders were washed twice with ethanol and distilled water respectively and maintained it for air drying at room temperature for $2 \mathrm{~h}$. Finally, as synthesized $\mathrm{ZnO}$ powder was annealed at $350^{\circ} \mathrm{C}$ for $1 \mathrm{~h}$. Then the resultant product was grinded into fine powders using mortar and pestle. The experimental set up is pictorially represented in Fig. 2. Herein when zinc acetate was treated with ammonium hydroxide, zinc hydroxide was formed. Upon hydrothermal treatment, zinc oxide was formed. The possible reaction mechanism is shown as follows:

$\mathrm{Zn}\left(\mathrm{OOH}_{3} \mathrm{C}\right) 2+2 \mathrm{NH}_{4} \mathrm{OH} \rightarrow \mathrm{Zn}(\mathrm{OH})_{2} \rightarrow \mathrm{ZnO}$

\subsection{Preparation of nanocomposites or nanoparticles}

The nanocomposites of green AgNPs and hydrothermally synthesized $\mathrm{ZnO}$ were prepared by solid-state reaction process at room temperature. For the synthesis of composite material $\mathrm{ZnO}$ and Green-AgNPs were taken in two different ratios such as $95: 05$ ratio for $5 \% \mathrm{w} / \mathrm{w}$ and $90: 10$ ratio for $10 \% \mathrm{w} / \mathrm{w}$. Then the mixture was grinded in electrical grinder for $3 \mathrm{~h}$. Whenever we uniformly grind the two components during solid state reactions practically there is no formation of any primary bonds. But there may be some weak physical force of attraction of repulsion in between the nanoparticles. This type of interaction may be due to secondary bonds like van Der wall's bond. Then the dried resultant compositeproduct or nanoparticles was kept at $450^{\circ} \mathrm{C}$ for 2 hin an electrical furnace for annealing. The annealed composite was stored in air tight glass bottle and used for characterization and study of biological effectiveness. The Green-AgNPs (5\%) and $10 \%$ incorporated in $\mathrm{ZnO}$ nanopowder or nancomposite are designated as $\mathrm{ZnO}-\mathrm{AgNPs}-5$ and $\mathrm{ZnO}-\mathrm{AgNPs}-10$ respectively. The experimental set up is pictorially represented in Fig. 3. 


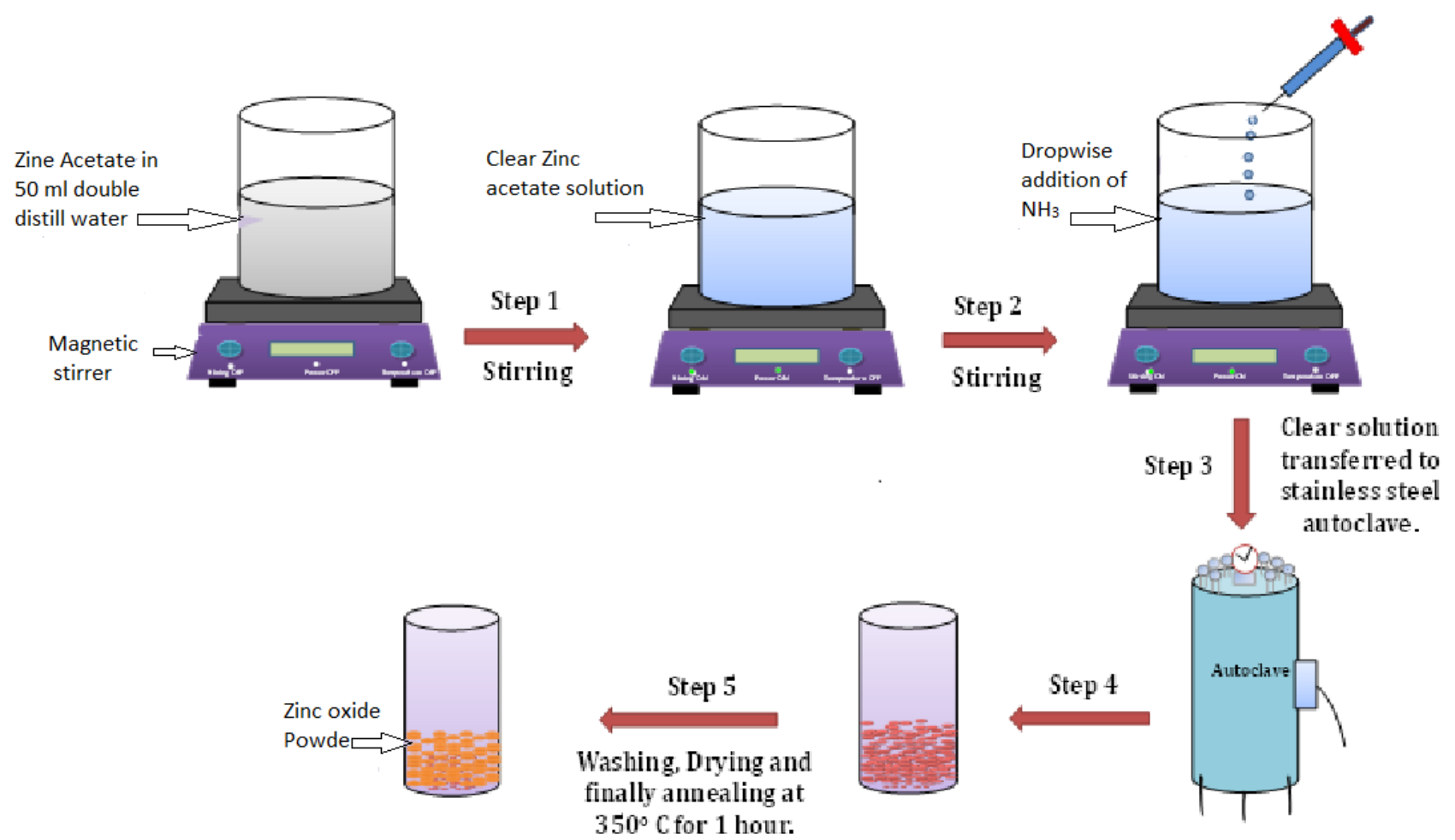

Fig. 2 Schematic diagrammatic representation of $\mathrm{ZnO}$ nanopowder synthesis.

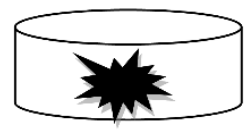

Green Ag nanopowder

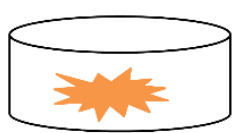

Zinc oxide powder

check elements present in composites by using Oxford instruments INCA with SEM (S4800), Hitachi Japan. Optical absorbance spectra of $\mathrm{ZnO}$, Green AgNPs and ZnO-AgNPs-5 and $\mathrm{ZnO}-A g N P s-10$ were analyzed by using (UV-vis (DRS)NIR V- 77O, JASCO, Japan spectrophotometer) in the wavelength range from 200 to $800 \mathrm{~nm}$.

\subsection{Determination of MIC}

The MIC value is considered as the lowest concentration of the sample, which inhibits the growth of a microbial culture. The MIC of all AgNPs, ZnO nanopowder and composite of $\mathrm{ZnO}-\mathrm{AgNPs}$ was determined by the broth dilution method. ${ }^{[21]}$ The freshly prepared cultures in nutrient broth was maintained at an absorbance of 0.1 at $600 \mathrm{~nm}$ (concentration of $108 \mathrm{CFU}$ $\mathrm{ml}-1$ ). Each $2 \mathrm{~mL}$ of broth culture was supplemented with 10 , $20,50,100$ or $200 \mu \mathrm{g} \cdot \mathrm{mL}^{-1}$ of sample solutions. Culture broths used without any sample served as control. All the tubes were incubated at $37^{\circ} \mathrm{C}$ for $24 \mathrm{~h}$. The experimental processes were repeated for three times. The growth of micro-organism in each tube was detected by colorimetric method at $600 \mathrm{~nm}$ and the concentration of the nanoparticles, at which no microbial growth was observed, was determined as the minimum inhibitory concentration.

\subsection{Characterization Study}

The crystal structures of Ag, $\mathrm{ZnO}$ NPs and composite of $\mathrm{ZnO}$ AgNPs were characterized by X-ray diffraction (Bruker AXS Analytical Instruments Pvt. Ltd., Germany, Model: D2 phaser). The surface morphology of AgNPs, $\mathrm{ZnO}$ powder and $\mathrm{ZnO}$ AgNPs-5 and ZnO-AgNPs-10 were studied using a scanning electron microscope (Model JEOL- JSM-6360, Japan), operated at an acceleration voltage $20 \mathrm{kV}$. The energy dispersive $\mathrm{X}$ - ray spectroscopy (EDAX) was carried out to 

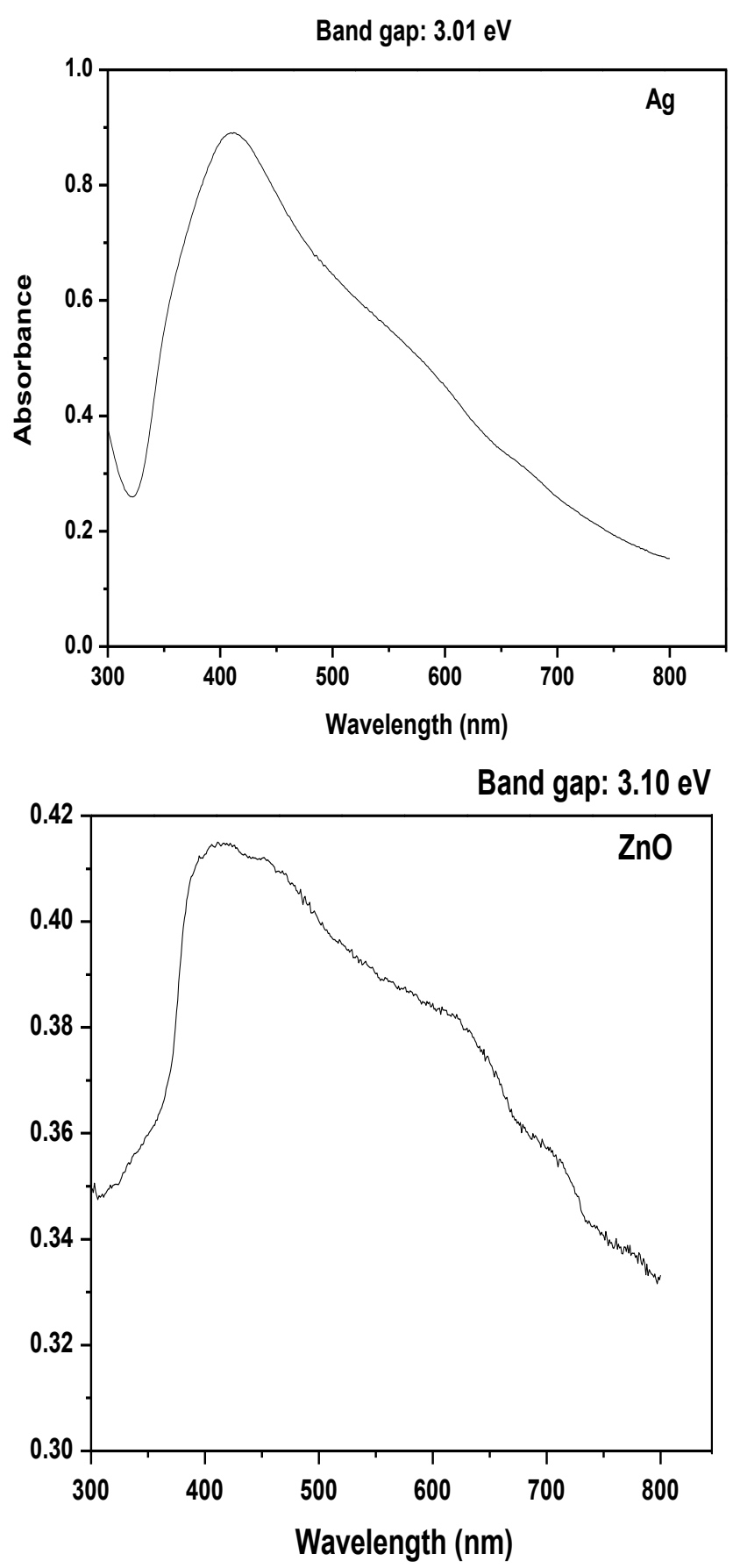

Fig. $4 \mathrm{UV}$-Visible curve of $\mathrm{Ag}$ and $\mathrm{ZnO}$ nanoparticle.

\subsection{Antimicrobial studies}

\subsubsection{Antibacterial study}

In vitro antimicrobial activity of aqueous extract of NPs were investigated against four different bacterial strain using agar well diffusion methods. ${ }^{[2]}$ Bacterial strain isolates examined included three Gram-negative bacteria: Escherichia coli (MNCL2832), Salmonella typhi (MNCL2501), Pseudomonas aeruginosa (MNCL5032), and oen Gram-positive bacterium Bacillus cereus (MNCL2703). Previously stored at $4^{\circ} \mathrm{C}$, bacterial strains were cultured on fresh nutrients agar plate and grown for 48 hours at $37{ }^{\circ} \mathrm{C}$. The plates for antimicrobial activity were prepared using submerged method and the wells were made using sterile cork borer. The prepared nanomaterials $\mathrm{ZnO}, \mathrm{AgNPs}$ and their $\mathrm{ZnO}-\mathrm{Ag}$ nanocomposites were sonicated in distilled water to obtain 1 $\mathrm{mg} / \mathrm{mL}$ stock solution. The stock solution was diluted with nutrient broth to $50,100,150$ and $200 \mu \mathrm{g} / \mathrm{mL}$ of working solutions. Then $100 \mu \mathrm{L}$ of each sample was aseptically introduced into the each well and plate were incubated for 1520 min at $40{ }^{\circ} \mathrm{C}$ in the refrigerators (Godrej India) for the sample diffusion. Then after the plates were transferred to the incubator for $24 \mathrm{~h}$ and maintained at $37{ }^{\circ} \mathrm{C}$ and the inhibitory zone around the wells was observed. The MQ distilled water was used as negative control and medium spectrum antibiotic Streptomycin was used as reference drug as positive control.

\subsubsection{Antifungal study}

In vitro antifungal activity of samples was determined using two different fungal strains namely Aspergillus niger (NCIM 1207), Fusarium solani (JALPK). Fungal strain of A. nigerwas procured from NCCS Pune India and Fusarium solani (JALPK) culture were isolated in our laboratory. ${ }^{[23]}$ Fungal spores of each strain were individually transferred to PDA agar (potato dextrose agar) using sterile forceps in aseptic conditions and grown for 48 hour. Then different concentrations $(50,100,150$ and $200 \mu \mathrm{g} / \mathrm{mL})$ of $100 \mu \mathrm{L}$ of samples of ZnO-AgNPs were introduced aseptically using micropipette in four different wells made in sterile PDA plate and the entire zone of inhibition was observed around the wells after 48 hours.

\subsection{Antioxidant potential}

The percentage inhibition of antioxidants was determined using DPPH (2,2-diphenyl-1-picryl- hydrazyl-hydrate) radical scavenging assay described with a slight modification. ${ }^{[24]}$ The $50 \mu \mathrm{L}$ of aqueous samples of $\mathrm{ZnO}, \mathrm{AgNPs}$ and their $\mathrm{ZnO}-\mathrm{Ag}$ composites (concentration $1 \mathrm{mg} / \mathrm{L}$ ) were reacted with $150 \mu \mathrm{L}$ of water and $3 \mathrm{~mL}$ stable DPPH radical in a methanol solution. The aliquot was shaken intensely and left to stand for 30 minutes in the dark condition. The reaction between DPPH radicals and antioxidant compound present in sample (which can donate hydrogen) was monitored spectrophotometrically at $517 \mathrm{~nm}$ (change in color from deep violet to light yellow was observed). Ascorbic acid was used as standard reference compound. The radical-scavenging activity (RSA) was calculated as a percentage of DPPH discoloration using the following formula (1):

$$
\text { DPPHRSA }(\%)=\left(A_{\text {control }}-A_{\text {sample }}\right) / A_{\text {control }} \times 100
$$

\subsubsection{Ferric reducing antioxidant power (FRAP) activity}

Ferric reducing antioxidant power (FRAP) was estimated as per method developed by Brand-Williams. ${ }^{[25]}$ FRAP reagent was prepared freshly and incubated at $37^{\circ} \mathrm{C}$. A working reagent was prepared freshly by mixing $10 \mathrm{~mL}$ of $300 \mathrm{mM}$ acetate buffer with $1 \mathrm{~mL}$ of $10 \mathrm{mM} \mathrm{2,4,6-tripyridyl-s-triazine}$ (TPTZ) in $40 \mathrm{mM}$ hydrochloric acid $(\mathrm{HCl}$ ) and $1 \mathrm{~mL}$ of 20 $\mathrm{mM} \mathrm{FeCl} l_{3} \cdot 6 \mathrm{H}_{2} \mathrm{O}$. Aqueous samples of $\mathrm{ZnO}$, AgNPs and their $\mathrm{ZnO}-\mathrm{Ag}$ composites react with fresh FRAP reagent and the color intensity was certified spectrophotometrically at $593 \mathrm{~nm}$ and reported in terms of optical density. Ascorbic acid was 
used as standard antioxidant compound. Capability of FRAP was measured in terms of optical density and compared with standard.
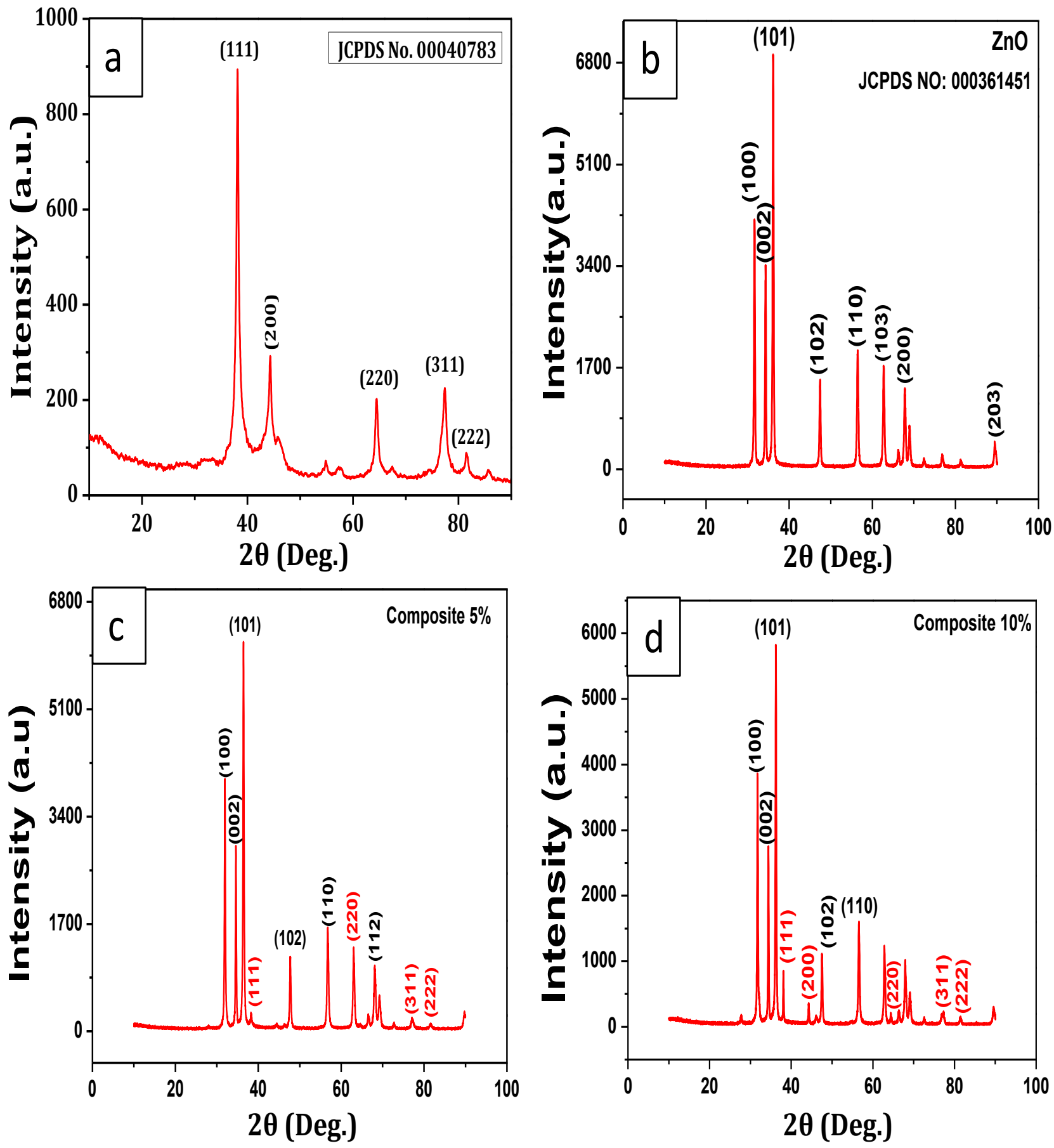

Fig. 5 XRD Pattern of a) ZnO, b) AgNPs, c) ZnO-AgNPs-5, and d) ZnO-AgNPs- 10 composite. 

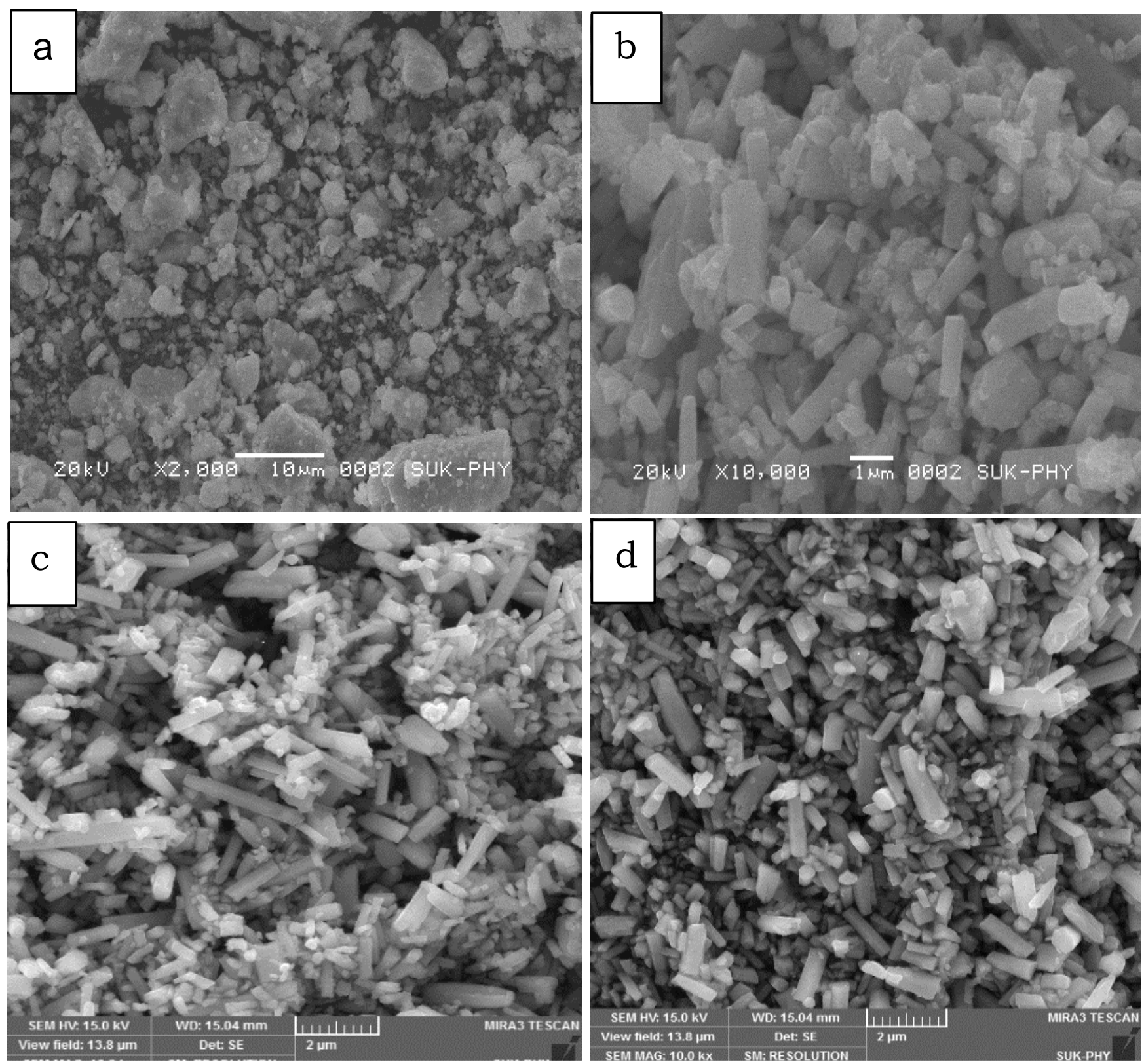

Fig. 6 SEM analysis of (a) Ag nanoparticles, (b) $\mathrm{ZnO}$ nanopowder, c) 5-95 \% Ag-ZnO composites, and d) $10-90 \% \mathrm{Ag}-\mathrm{ZnO}$ composites.

\subsection{Dye degradation potential of nanomaterials}

Dye is a high molecular weight colored compound that is chemically bonds to the substrate (suh as generally fabric). Dyes are generally soluble in water whereas pigments are insoluble in water. Except a number of dyes available from natural sources, many more are synthesized artificially in the laboratory. The color of the dye depends on chromophore, which imparts the color and auxochrome to intensify the color. However extensive use of dyes particularly in textile industries has heavy polluted the natural water resources such as river etc. Due to high molecular weight, the degradation of dye becomes difficult. The dye in water reservoir affects color, odor and other physico-chemical properties of water.

The dye solutions were prepared using distilled water in the dark room. $500 \mathrm{~mL}$ of distilled water was taken in the 1000
$\mathrm{mL}$ beaker, and then $5 \mathrm{mg}$ of MB dye was slowly added. Then the solution was wrapped completely with aluminum foil to prevent any kind of light. After this, in the prepared dye solution, the synthesized nanomaterials such as $\mathrm{ZnO}, \mathrm{ZnO}$ AgNPs-5 and ZnO-AgNPs-10 were added to three beakers separately as a catalyst along with pre-prepared dye sample in the proportion of 1:1 (i.e. $50 \mathrm{~mL}$ of dye and $50 \mathrm{~mL}$ of catalyst) ratio. One more beaker containing only dye solution was maintained acted as the control. Likewise, all the four beakers were maintained in darkness. The beakers containing catalyst were stirred on magnetic stirrer for 30 minutes. This resulted in complete dispersion of synthesized nanomaterials. The experiments were carried out in the sunlight at the ambient temperature between 25 and $30^{\circ} \mathrm{C}$ and the average intensity of sunlight during this period was observed about $850-950$ 
au. ${ }^{[21]}$ The $1 \mathrm{mg} / \mathrm{mL}$ of concentration of $\mathrm{ZnO}$ nanoparticle was used for dye solution. The progress of photocatalytic degradation was monitored by withdrawing specific amount of sample at different intervals. The percentage of degradation was calculated by Equaation (2);
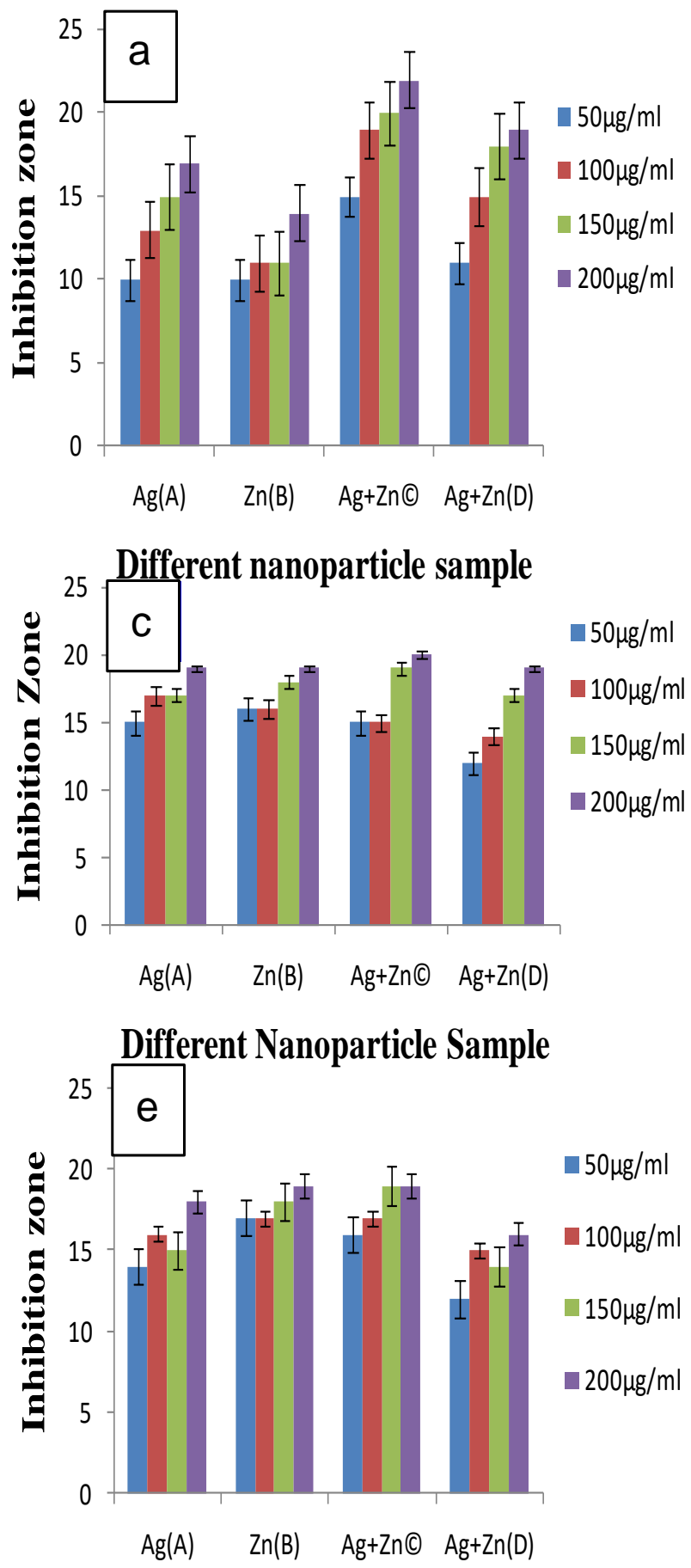

Different Nanoparticle Sample
Degradation $(\%)=\frac{\mathrm{C}_{0-C_{e}}}{C_{0}} \times 100$

where $\mathrm{C}_{0}$ and $C_{e}$ are the dye initial concentration and dye concentration after the photocatalytic treatment.
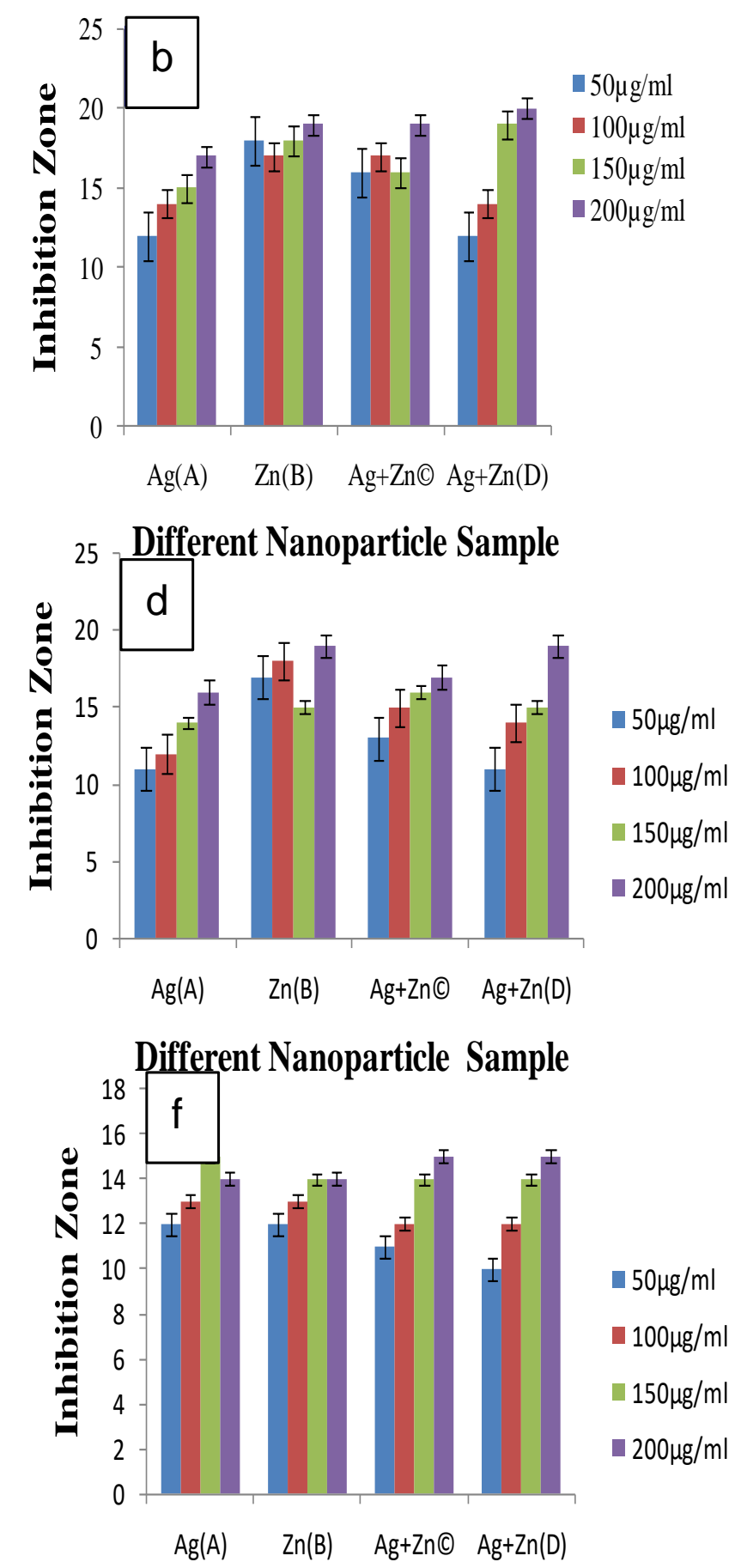

Different Nanoparticle sample

Fig. 7 Antibacterial \& antifungal activity of biosynthesized AgNPs, chemically synthesized ZnO nanopowder and composite of both $\mathrm{Ag}$ and $\mathrm{ZnO}$ nanoparticles at different concentrations. 


\section{Results and Discussion:}

\subsection{UV-visible analysis}

At the end of experimentation process, the obtained black colored powder is $\mathrm{Ag}$ and the white colored powder is $\mathrm{ZnO}$. Both nanopowders were insoluble in MQ water, the well dispersed solution was obtained by sonicating for $30 \mathrm{~min}$. Then the completely dispersed upper part of solution was taken into a quartz cuvette and exposed to UV-visible radiation. Fig. 4 shows the UV-Vis spectra. Here, maximum absorption is observed at $410 \mathrm{~nm}$, which is in good agreement with the reported values for ZnONPs. The peak at $390 \mathrm{~nm}$ is in good agreement with the reported values for AgNPs. However, the surface plasmon resonance (SPR) absorbance is sensitive to the nature, size and shape of particles present in the solution. With increasing the particle size, the absorption band shifts towards red. The inter particle distance and the surrounding media also affect the absorption bands.

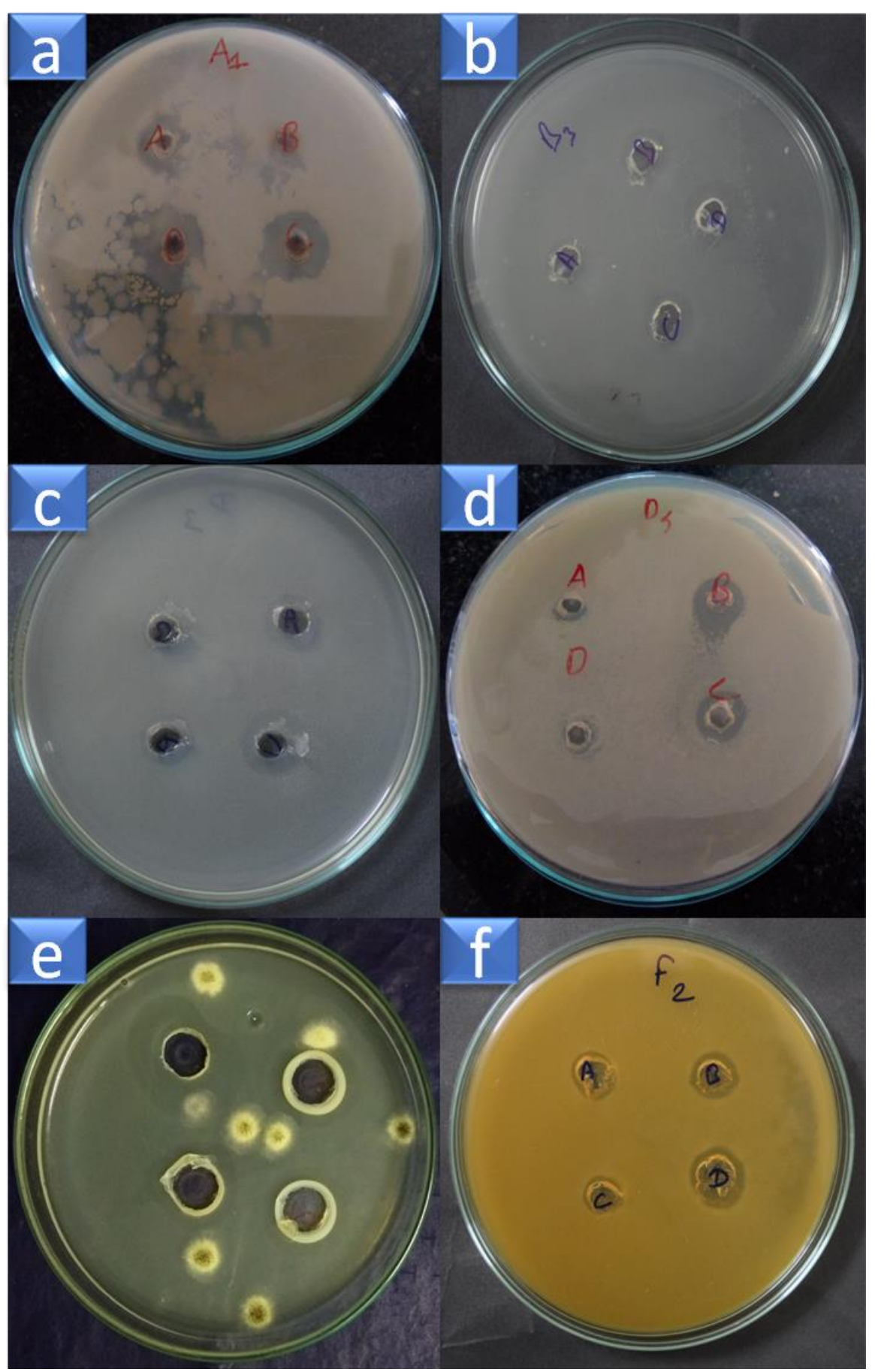

Fig. 8 Antimicrobial activity of nanoparticle against different microbial strains a) Escherichia coli, b) Salmonella typhi, c) Bacillus cereus, d) Pseudomonas aeruginosa, e) Aspergilus niger, f) Fusarium solani. 


\subsection{XRD study}

In order to identify the nature of the biosynthesized AgNPs and chemically synthesized $\mathrm{ZnO}$ nanopowder as well as $\mathrm{ZnO}$ AgNPs-5 and ZnO-AgNPs-10 nano-composites, the X-Ray diffraction technique was implemented. The XRD pattern reveals the formation of poly- dispersed crystalline nanomaterials, Fig. 5. The reflections from AgNPs reveal cubic nature of particles as reported (111), (200), (220), (311) and (222) with the corresponding values 38.23, 44.22, 64.70, 77.51 and 81.54, respectively (JCPDS 04-0783). While the reflections from $\mathrm{ZnO}$ nanopowders reveal a hexagonal nature, having the (100), (002), (101), (102), (103), and (200) and (203) with the corresponding values 33.76, 34.50, 36.16, 47.36, $56.45,62.80,67.98$ and $89.68^{\circ}$, respectively (JCPDS NO: $000361451)$. Furthermore, the reflections of $5 \%$ composites of Ag-ZnO correspond to the (100), (002), (101), (102), (110) and (112), the $\theta$ values are $31.96,34.70,36.46,47.63,56.85$ and $68.21^{\circ}$, respectively. These are the hkl values for the XRD obtained for the $\mathrm{ZnO}$ nanopowders. Similarly, (111), (220), (311) and (222) are the hkl values obtained for the Ag and the corresponding $2 \theta$ value is $38.42,62.93,77.03$, and $81.73^{\circ}$, respectively. For $10 \%$ composites, the reflections are (100), (002), (101), (102), and (110) and $\theta$ is $31.76,34.50,36.17$, 47.65 and $56.45^{\circ}$, respectively. Similarly, (111), (200), (220), (311) and (222) are the hkl value of the $\mathrm{Ag}$, and the corresponding $2 \theta$ values are 38.02, 44.28, 66.32, 76.93 and $81.47^{\circ}$, respectively.

\subsection{Surface morphology}

Fig. 6 depicts the SEM images of synthesized AgNPs, ZnO nanopowder and $\mathrm{ZnO}$-AgNPs-5 and ZnO-AgNPs-10 nanocomposites. Fig. 6(a) shows the image of AgNPs. A large number of nanoparticles are spherical in shape with the diameter in the range of 1.1-1.5 um. The shape, size distribution and morphology of the prepared $\mathrm{ZnO}-\mathrm{AgNPs}-5$ and $\mathrm{ZnO}$-AgNPs-10 composites are shown in Fig.6(c-d), which reveals that the major percentage of composites are in nano- rods shape with the size lying in the range between 0.3 $0.4 \mathrm{~mm}$.

In addition to understand how the size, shape, surface, and aggregation state of the $\mathrm{Ag}$ and $\mathrm{ZnO}$ nanopowder change after integration into each other, how it makes a perfect blending is a challenging task. ${ }^{[26]}$ But the SEM images confirmed the pebble shaped $\mathrm{ZnO}$ nanopowder and rod shaped AgNPs. The $\mathrm{ZnO}$-AgNPs composites with different concentrations show an intermediate structure. Furthermore, during mechanical grinding, the rod-shaped structures are broken into small pieces which can be clearly seen in the images.

\subsection{Minimum inhibitory concentration}

Comparative studies of different four samples containing $\mathrm{ZnO}-\mathrm{AgNPs}$ composite and $\mathrm{ZnO}$, AgNPs are determined for their minimum inhibitory concentration against four laboratory used microbes (out of which, few are pathogenic to human body). Results are given in Table1, demonstrating the noteworthy effectiveness of the composite made from $\mathrm{ZnO}$ and AgNPs (10\%) concentration against all microbes under study. Results also reveal that bacterial strain of $B$. cereus has good inhibitory activity among all four bacterial strain in various concentrations.

The efficiency order of strains against composite of 5-95\% Ag- $\mathrm{ZnO}$ and $10-90 \% \mathrm{Ag}-\mathrm{ZnO}$ is B. cereus $>$ E. coli $>$ S. typhi $>P$. aeruginosa and $B$. cereus $>$ E. coli $>$ P. aeruginos $a$. typhi, respectively. Generally, the size, specific surface area and shape are key factors responsible for toxicity (antibacterial activity) to the bacterial strain, which can be changed by changing the synthesis parameters of the nanoparticles and nanocomposites. Good strength of B. cereusare is observed in all four samples. This bactericidal property of the nanomaterial is co-related with the specific surface area and particle size of the material, which deals with the biological activity like membrane permeability, enzyme inactivation and production of reactive oxygen species (ROS). The synthesized NPs and nanocomposite using green approach were found to have a good antibacterial potential.

Table 1. Optical density of the nutrient broth containing culture and different concentrations of $\mathrm{ZnO}$ and AgNPs after 24 hours for determination of bacterial growth.

\begin{tabular}{|c|c|c|c|c|c|c|}
\hline $\begin{array}{l}\text { Sample } \\
\text { Name }\end{array}$ & $\begin{array}{r}\text { Conc } \\
\mu \mathrm{g} / \mathrm{mL}\end{array}$ & E. coli & S. typhi & $\begin{array}{c}\text { B. } \\
\text { cereus }\end{array}$ & $\begin{array}{c}P . \\
\text { aeruginosa }\end{array}$ & $\begin{array}{l}\text { Streptomycin } \\
\text { (STD) }\end{array}$ \\
\hline \multirow[t]{4}{*}{$\mathrm{ZnONPs}$} & 25 & 0.15 & 0.22 & 0.10 & 0.18 & 0.01 \\
\hline & 50 & 0.08 & 0.17 & 0.05 & 0.08 & 0.00 \\
\hline & 100 & 0.07 & 0.11 & 0.00 & 0.04 & 0.00 \\
\hline & 200 & 0.06 & 0.04 & 0.00 & 0.01 & 0.00 \\
\hline \multirow[t]{4}{*}{ AgNPs } & 25 & 0.14 & 0.21 & 0.12 & 0.17 & 0.00 \\
\hline & 50 & 0.08 & 0.14 & 0.05 & 0.06 & 0.00 \\
\hline & 100 & 0.04 & 0.09 & 0.02 & 0.05 & 0.00 \\
\hline & 200 & 0.00 & 0.01 & 0.00 & 0.02 & 0.00 \\
\hline \multirow{4}{*}{$\begin{array}{l}\mathrm{ZnO}-\mathrm{Ag}- \\
5 \%\end{array}$} & 25 & 0.11 & 0.11 & 0.06 & 0.10 & 0.02 \\
\hline & 50 & 0.08 & 0.05 & 0.02 & 0.08 & 0.00 \\
\hline & 100 & 0.02 & 0.04 & 0.00 & 0.04 & 0.00 \\
\hline & 200 & 0.00 & 0.00 & 0.00 & 0.01 & 0.00 \\
\hline \multirow{4}{*}{$\begin{array}{l}\mathrm{ZnO}-\mathrm{Ag}- \\
10 \%\end{array}$} & 25 & 0.13 & 0.16 & 0.06 & 0.12 & 0.00 \\
\hline & 50 & 0.07 & 0.11 & 0.01 & 0.07 & 0.00 \\
\hline & 100 & 0.04 & 0.05 & 0.00 & 0.08 & 0.00 \\
\hline & 200 & 0.00 & 0.04 & 0.00 & 0.02 & 0.00 \\
\hline
\end{tabular}


Table 2. Zone of inhibition (in $\mathrm{mm}$ ) observed in different bacterial and fungal strains (zone of inhibition in $\mathrm{mm}$, $\mathrm{n}=3$ ).

\begin{tabular}{|c|c|c|c|c|c|c|c|}
\hline \multirow[b]{2}{*}{ Sample name } & \multirow[b]{2}{*}{$\begin{array}{r}\text { Conc } \\
\mu \mathrm{g} / \mathrm{mL}\end{array}$} & \multicolumn{4}{|c|}{ Antimicrobial activity } & \multicolumn{2}{|c|}{ Antifungal activity } \\
\hline & & E. coli & S. typhi & B. cereus & $P$. aeruginosa & A. niger & F. solani \\
\hline \multirow[t]{4}{*}{ Silver (A) } & 50 & $10 \pm 0.14$ & $12 \pm 0.47$ & $15 \pm 0.94$ & $11 \pm 0.65$ & $12 \pm 0.55$ & $12 \pm 0.36$ \\
\hline & 100 & $13 \pm 0.35$ & $14 \pm 0.69$ & $17 \pm 0.14$ & $12 \pm 0.34$ & $14 \pm 0.20$ & $13 \pm 0.75$ \\
\hline & 150 & $15 \pm 0.54$ & $15 \pm 0.44$ & $17 \pm 0.47$ & $14 \pm 0.71$ & $15 \pm 0.59$ & $14 \pm 0.32$ \\
\hline & 200 & $17 \pm 0.32$ & $17 \pm 0.36$ & $18 \pm 0.36$ & $16 \pm 0.40$ & $16 \pm 0.33$ & $14 \pm 0.36$ \\
\hline \multirow[t]{4}{*}{ Zinc (B) } & 50 & $10 \pm 0.11$ & $16 \pm 0.41$ & $16 \pm 0.70$ & $15 \pm 0.33$ & $13 \pm 0.46$ & $12 \pm 0.98$ \\
\hline & 100 & $11 \pm 0.45$ & $17 \pm 0.96$ & $16 \pm 0.89$ & $18 \pm 0.67$ & $15 \pm 0.84$ & $13 \pm 0.54$ \\
\hline & 150 & $11 \pm 0.22$ & $18 \pm 0.77$ & $18 \pm 0.34$ & $15 \pm 0.47$ & $16 \pm 0.22$ & $14 \pm 0.97$ \\
\hline & 200 & $14 \pm 0.17$ & $17 \pm 0.40$ & $18 \pm 0.73$ & $17 \pm 0.17$ & $17 \pm 0.38$ & $14 \pm 0.81$ \\
\hline \multirow{4}{*}{$\begin{array}{c}\text { Silver+Zinc } \\
\text { (C) }\end{array}$} & 50 & $15 \pm 0.59$ & $16 \pm 0.37$ & $15 \pm 0.21$ & $13 \pm 0.30$ & $15 \pm 0.21$ & $11 \pm 0.35$ \\
\hline & 100 & $19 \pm 0.62$ & $17 \pm 0.66$ & $15 \pm 0.18$ & $15 \pm 0.59$ & $16 \pm 0.34$ & $12 \pm 0.63$ \\
\hline & 150 & $20 \pm 0.38$ & $16 \pm 0.24$ & $19 \pm 0.65$ & $16 \pm 0.58$ & $15 \pm 0.37$ & $14 \pm 0.80$ \\
\hline & 200 & $22 \pm 0.55$ & $19 \pm 0.47$ & $20 \pm 0.46$ & $17 \pm 0.50$ & $17 \pm 0.77$ & $15 \pm 0.67$ \\
\hline \multirow{4}{*}{$\begin{array}{l}\text { Silver+Zinc } \\
\text { (D) }\end{array}$} & 50 & $11 \pm 0.19$ & $12 \pm 0.33$ & $12 \pm 0.73$ & $11 \pm 0.11$ & $12 \pm 0.51$ & $10 \pm 0.94$ \\
\hline & 100 & $15 \pm 0.12$ & $14 \pm 0.84$ & $14 \pm 0.61$ & $14 \pm 0.38$ & $14 \pm 0.65$ & $12 \pm 0.33$ \\
\hline & 150 & $18 \pm 0.64$ & $17 \pm 0.33$ & $17 \pm 0.82$ & $15 \pm 0.46$ & $14 \pm 0.47$ & $12 \pm 0.24$ \\
\hline & 200 & $19 \pm 0.52$ & $20 \pm 0.69$ & $19 \pm 0.73$ & $18 \pm 0.47$ & $15 \pm 0.87$ & $13 \pm 0.54$ \\
\hline
\end{tabular}

\subsection{Antimicrobial activities}

The antibacterial and antifungal activities of four different samples (two nanoparticle extracts and two composite) were evaluated against a set of four microorganisms and two fungal strains. At primary level, the competence inhibition concentration of test samples against microorganisms were tested using MIC and further strength was assessed qualitatively for their presence or absence of inhibitory zone.

\subsubsection{Antibacterial activity}

An agar well diffusion technique is the extensively used method to learn the antimicrobial activity of various samples. The results represented in Table 2 indicate that the given tested concentrations of nanoparticles and composite extract are having a significant antimicrobial activity against tested microbes. With the increase in the concentration of the sample, the zone of inhibition increases due to the bactericidal activity of NPs that produces large zone by killing the test microbes. The zone of inhibition (in millimeter) of each well was measured and the values were noted and depicted in Table 2 (values are in between $10 \pm 0.11$ to $22 \pm 0.55$ ). Moderately good antibacterial activities against $E$. coli and B. cereus were demonstrated by all four samples. Nanocomposites showed a better activity than the individual $\mathrm{ZnO}$ and AgNPs.

As the concentration of the sample was increased, the zone of inhibition was also increased, which is in an agreement with previous reports. ${ }^{[21-33]}$ As compared with other microbes under study, E. coli found minimum antimicrobial spectrum. The AgNPs, ZnONPs, composite of ZnONPs with a proportion of $5 \%$ and $10 \%$ AgNPs and vice-versa were used in study to check their zone of inhibition. The composites of $5 \% \mathrm{AgNPs}$ and $10 \%$ ZnoNPs concentration were showed a higher zone of inhibition. The composites of 5\% AgNPs and 10\% ZnoNPs concentration showed a higher zone of inhibition. Meanwhile, the comparative study of AgNPs and $\mathrm{ZnO}$ for the zone of inhibition shows higher results within $\mathrm{ZnO}$ addition. The antimicrobial activity result is phographically represented in Fig. 7. Meanwhile, the remarkable, resistance for antibiotic is observed due to poor antibiotic penetration and adaptive bacterial response. ${ }^{[34,35]}$ This increases the need of finding new antibiotic, which has been fulfilled by making composites of different nanoparticle composites with various concentrations. These produced new composites are thus useful in various applications like plant, food, physical, medical and veterinary sciences. Streptomycine is a medium spectrum antibiotic, 
which is widely used against anaerobic bacterium. This considering the multiple applications of drug Streptomycin, it medicine is used against Tuberculosis caused by is used as positive control.

Mycobacterium, diarrhoea caused by Salmonella and cattle disease HS that is a widely spreading cattle disease. Therefore,

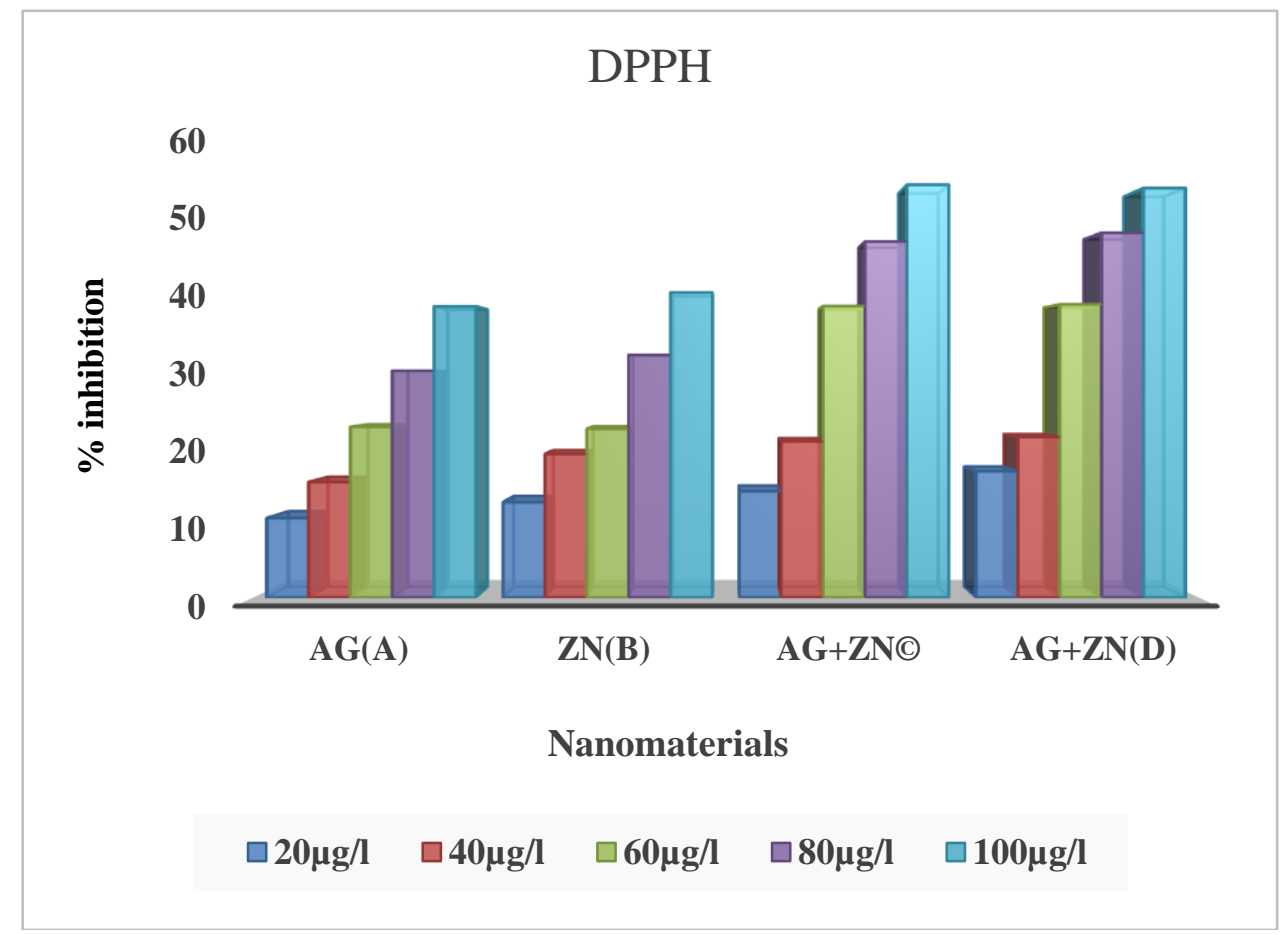

Fig. 9 Bar chart of different concentrations of nanomaterials against \% inhibition of DPPH. 1) AgNPs, 2) ZnO nanopowder, 3) Composite of ZnO-AgNPs-5, and 4) ZnO-AgNPs-10, (Mean \pm SD, n=3).

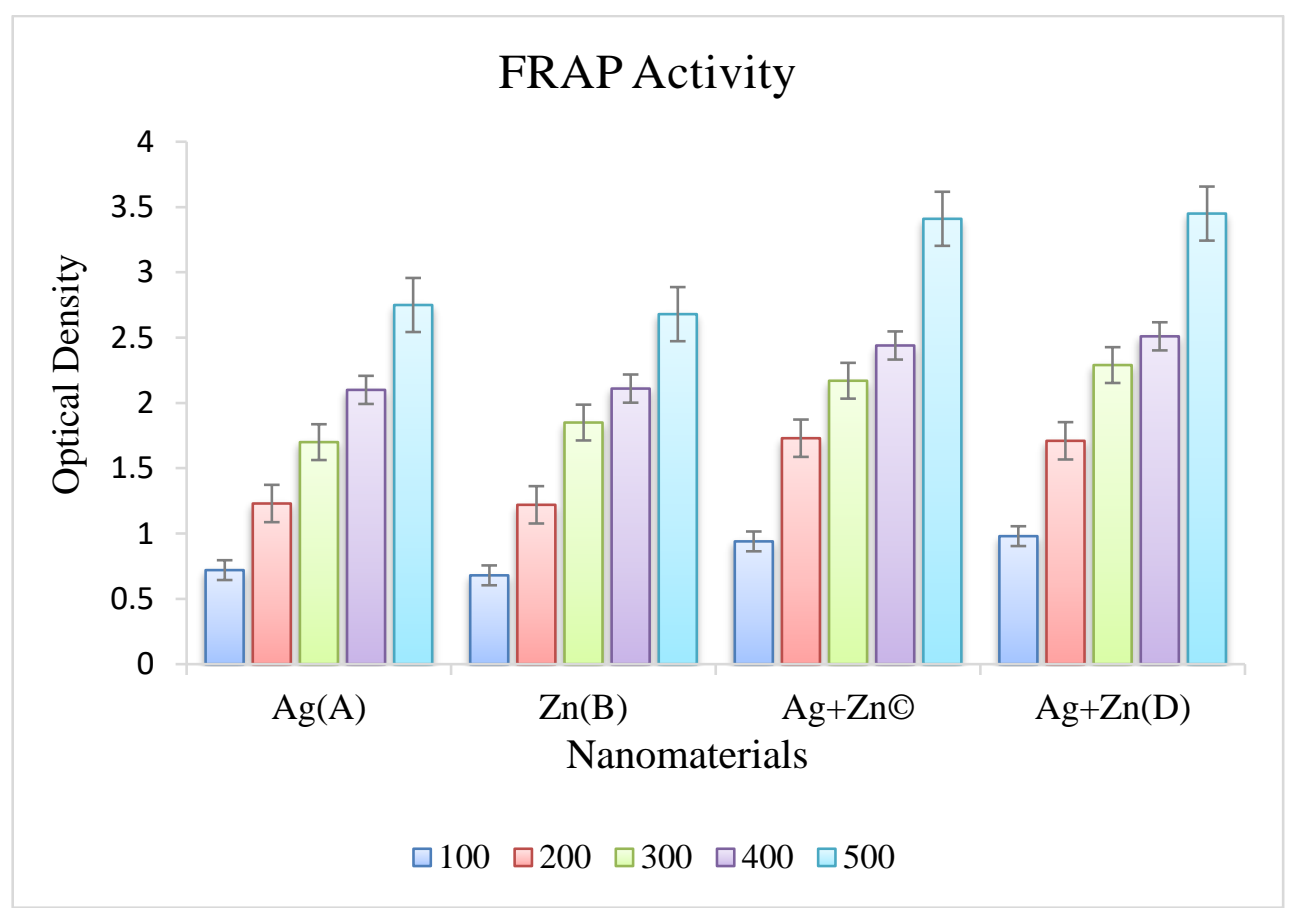

Fig. 10 Comparison of Ferric reducing power activity in the form of OD of nanomaterial prepared from 1) $\mathrm{ZnO}, 2$ ) AgNPs, 3) composite of $\mathrm{ZnO}-\mathrm{AgNPs}-5$ and 4)ZnO-AgNPs-10 (Mean $\pm \mathrm{SD}, \mathrm{n}=3$ ). 

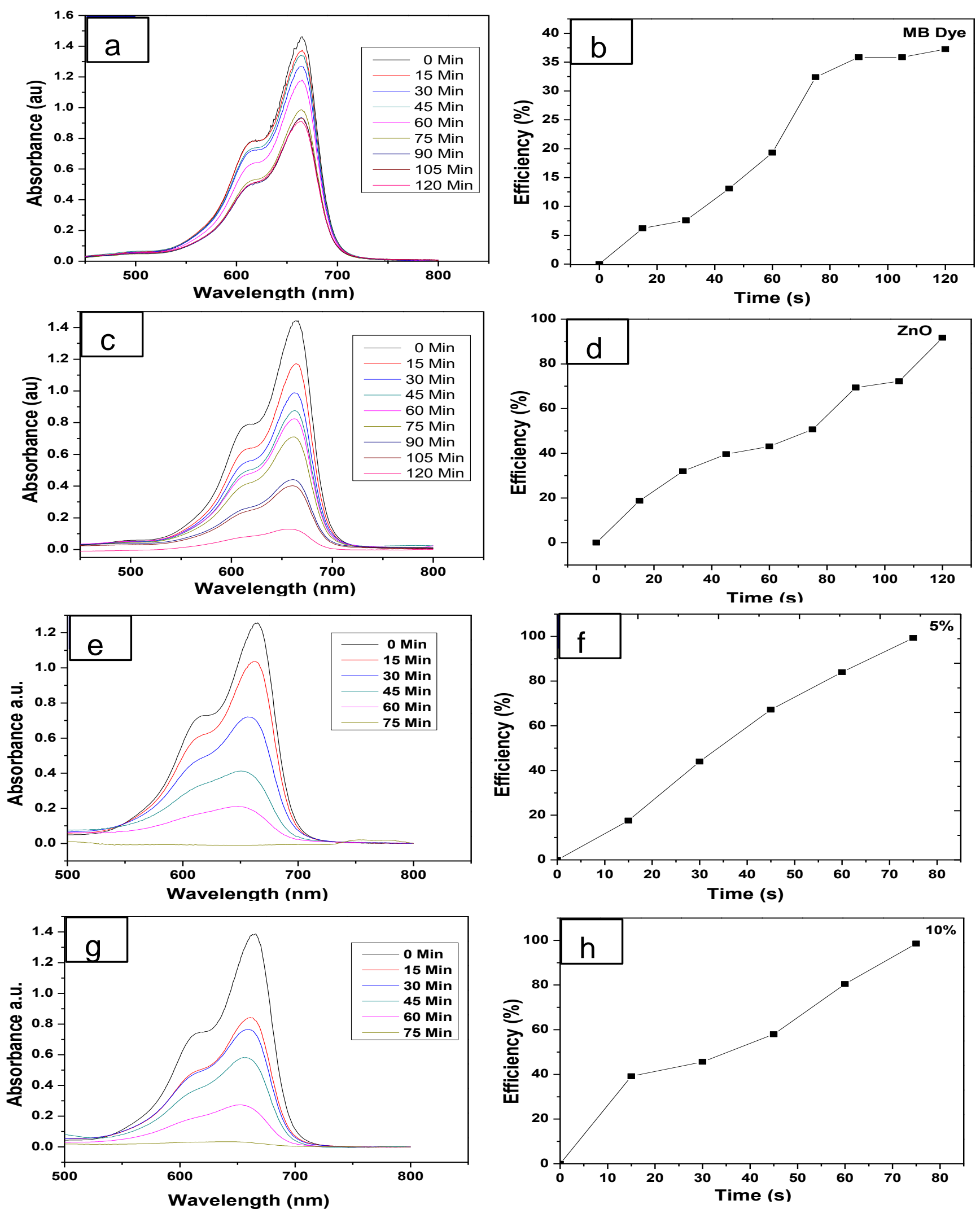

Fig. 11 Absorption spectra of reduction of methylene blue dye and \% degradation of methylene blue dye, Presence of (a-b) without catalyst (c-d), $\mathrm{ZnO}$ (e-f), composite of $\mathrm{ZnO}+\mathrm{Ag} 5 \%$ and (g-h), and Composite of $\mathrm{ZnO}+\mathrm{Ag} 10 \%$, respectively. 


\subsubsection{Antifungal activity}

The antifungal activity was screened by agar well diffusion method against two different fungal strains named as Aspergillus niger and Fusarium solani. ${ }^{[28]}$ These two fungi strains were treated with $100 \mu \mathrm{L}$ of the nanocompounds in different proportions (i.e., 50, 100, 150 and $200 \mu \mathrm{g} / \mathrm{mL}$ ). Then the culture was inoculated in the petri dish with sterile PDA media and incubated for $48 \mathrm{~h}$ at $37^{\circ} \mathrm{C}$. Nanomaterials used here are AgNPs, $\mathrm{ZnO}$, composites of $\mathrm{ZnO}$ with a proportion of $5 \%$ and $10 \%$ AgNPs. Finally, the obtained values are calculated in average and expressed in Table 2. The obtained results conclude that $A$. niger shows a higher zone of inhibition $(19 \mathrm{~mm})$ than F. solani $(14 \mathrm{~mm})$. The composite of AgNPs and $\mathrm{ZnO}$ with $5 \%$ of proportion $\mathrm{Ag}$ composite has a higher zone of inhibition (22 $\mathrm{mm}$ ) as compared to other compounds. All the results obtained in the study are having a good agreement with each other and may be used to prepare good fungicidal agent. The anti-fungal activity result is graphically represented in Fig. 8.

\subsection{Antioxidant activity}

\subsubsection{DPPH potential of nanoparticles and composites}

Results demonstrate that DPPH radical color disappears by antioxidants present in the samples. This color intensity is measured spectrophotometrically at $517 \mathrm{~nm}$ absorbance. The antioxidant activity of sample was measured in \% inhibition and it ranged from 10.62 to $55.12 \%$. This shows a positive correlation with concentration of samples. These results are correlated with the biogenic nanoparticles prepared from plant source ${ }^{[29]}$ Findings presented in the Fig. 9, clearly demonstrate a good antioxidant activity in composites of the $10 \%$ AgNPs, i.e $55.12 \pm 0.37 \%$, than the other three sample containing $5 \%$ $\mathrm{Ag}$ i.e $54.68 \pm 0.25 \%, \mathrm{ZnO}$ i.e $40.74 \pm 0.39 \%$ and AgNPs i.e $38.89 \pm 0.21 \%$ at $100 \mu \mathrm{g} / \mathrm{L}$ of sample concentration. The order of antioxidants present in the sample as assessed by DPPH radical scavenging activity is $\mathrm{ZnO}-\mathrm{Ag}-10>\mathrm{ZnO}-\mathrm{Ag}-5>$ AgNPs $>\mathrm{ZnO}$. Very small activity difference is demonstrated, which is approxmataly $1 \%$ between the $10 \%$ and $5 \%$ AgNPs

\subsubsection{FRAP potential of nanoparticles and composites}

Measurement of free radical molecules using Ferric reducing antioxidant potential is common method, where $\mathrm{Fe}^{3+}$ gets reduced into $\mathrm{Fe}^{2+}$. Results of this assay determined in the form of optical density are presented in Fig. 10. FRAP shows the activity in between 0.72 to 3.45 O.D at $595 \mathrm{~nm}$ absorbance at given concentrations. This shows a possible implantation of nanomaterial in the field of drug delivery and other fields of medicinal science. Among all the four samples, nanomaterial composite synthesized by using AgNPs-10 shows the highest activity ( $3.45 \pm 0.04$ OD), which can be used to neutralize the oxidative stress produced by cell, and thus can be employed in the management of chronic diseases in human beings. Present investigation also proves good antioxidant activity of composite produced from $\mathrm{ZnO}$ and AgNPs than that imparted by the produced singlet nanoparticle, i.e., $\mathrm{ZnO}(2.68 \pm 0.07)$ and AgNPs (2.75 \pm 0.02 ) optical density at $100 \mu \mathrm{g} / \mathrm{L}$ of sample concentration Therefore, this will definitely provide good platform to produce nanomaterials with a high potency for applications in numerous fields. Both antioxidant assays show good correlation of activity.

\subsection{Degradation of MB dye}

Methylene blue (MB) is used to treat urinary tract infection and is also used as dye or staining agent. This may be used as antiseptic possibly. Silica nanoparticles-based technologies have been used for removal of dyes from water. ${ }^{[36]}$ In order to investigate the photocatalytic degradation of MB dye, chemically synthesized $\mathrm{ZnO}$ nanopowder and its blending with AgNPs (i.e. $5 \%$ and $10 \%$ proportion) are added separately to the sample in the presence of sunlight. Initially, the prepared dye solution was kept in sunlight without adding catalyst and the sample was collected after every $15 \mathrm{~min}$ of time interval to check the results.

The spectrophometric analysis revealed that $37.76 \%$ dye was degraded under the natural sunlight which took about 120 min as shown in Fig. 11. The degradation of MB was monitored by UV-Vis spectroscopy and the absorption spectra were recorded in the range between $400-800 \mathrm{~nm}$. The absorption peak of MB dye was found to be centered at 664 $\mathrm{nm}$ and shoulder peak at $614 \mathrm{~nm}$ in visible region. Peaks are found to be decreased with an increase in time intervals. Due to redox reaction, the concentration of $\mathrm{MB}$ is in decreasing order with increase in time. When $\mathrm{ZnO}$ was added to the $\mathrm{MB}$ as catalyst, $91.67 \%$ degradation was observed after $120 \mathrm{~min}$. Afterwards, composite of ZnO-AgNPs-5 and ZnO-AgNPs- 10 were added to the $\mathrm{MB}$ as a catalyst, $99.21 \%$ and $97.71 \%$ dye were found to be degraded within $75 \mathrm{~min}$, respectively. Composites of $\mathrm{ZnO}-\mathrm{AgNPs}-5$ proportion showed the better results of all as mentioned above. Obtained results of dye degradation absorption plot is depicted in Fig. 11(a-h). The degradation of $\mathrm{MB}$ is in an increasing order with increasing time, i.e., time and degradation are in a directly proportional manner.

\subsection{Importance of biological method for preparation of nanoparticles.}

Generally, the syntheses of nanoparticles are carried out using three important methods, such as hydrothermal method, biological method and solid state reaction method. Our key purpose is to highlight the biological synthesis of nanoparticles because of the ease of its rapid synthesis and eco-friendly synthesis. The toxicity and size characterization can be controlled. Gold, silica, silver and many other nanoparticles are synthesized using Geranium extract, Aloe Vera plant extracts, Curcumin, Moringa oleifera, sundried Cinnamomum camphora and Azadiracta indica leaf extract, neem plant extract. ${ }^{[37-39]}$ Synthesis of nanoparticles using bacteria has been enlarged comprehensively. ${ }^{[40-43]}$ Bacillus species has been depicted to synthesize metal nanoparticles. ${ }^{[44]}$

The solid-state reaction route is one of the most widely used methods for the preparation of polycrystalline solids from a mixture of solid starting materials. Solids do not react 
together at room temperature over normal time scales and it is necessary to heat them to much higher temperatures. The factors, on which the feasibility and rate of a solid state reaction depend, include reaction conditions, structural properties of the reactants, surface area of the solids, their reactivity. These are the solid reactants, from which it is proposed to prepare a solid crystalline compound. The selection of reactant chemicals depends on the reaction conditions and expected nature of the product. After the reactants have been weighed out in the required amount, they are mixed. For manual mixing of small quantities, an agate mortar and pestle are employed. Sufficient amount of some volatile organic liquid preferably acetone or alcohol is added to the mixture to aid homogenization. This forms a paste, which is mixed thoroughly. During the process of grinding and mixing, the organic liquid gradually volatilizes and has usually evaporated completely after 10 to $15 \mathrm{~min}$. For the subsequent reaction at high temperatures, it is necessary to choose a suitable container material, which is chemically inert to the reactants under the heating conditions. The heating program to be used depends on the form and reactivity of the reactants. In the control of either temperature or atmosphere, natures of the reactant chemicals are considered. A noncorrosion furnace is used for heat treatment.

\section{Conclusions}

Biogenic synthesis of silver and hydrothermal synthesis of $\mathrm{ZnO}$ nanoparticles have been demonstrated. This is a rapid and eco-friendly method, which has added advantage of reduced reaction time and better control over size and morphology. This is very simple and does not require sophisticated instrumentation and high skilled man power. This is very economical as Gongura leaves are used as reducing agent which is easily available. The nanoparticles can be synthesized at physiological $\mathrm{pH}$. The synthesized nanoparticles are mostly cylindrical, and poly-disperse. Antimicrobial activities have been obtained against the tested micro-organisms in these nnaomateirals. This antimicrobial activity benefits to the synthesis of new antimicrobial agents and use in medicinal science. Thus, the present study reports a new approach to obtain nanopartilcels with a potential for UV protection, dyedegradation, antifungal and, antibacterial areas.

\section{Acknowledgement}

The authors pay sincere tribute to Late Ms Deepika Rai Dhirendra Prasad who suddenly passed away. The authors are thankful to Dr.T.D. Dongale, Mr. Mahesh Chougule, Mr. Prashant Sarvalkar and Dr. Krishna Pawar for possible help during the progress of research work. Suresh Suryawanshi sincerely thanks to Indian Council of Medical Research (ICMR) for providing SRF fellowship Award No. 45/6/2019/MP/BMS]. Authors are greatly acknowledged to head Department of Biotechnology, Shivaji University, and Kolhapur.

\section{Supporting Information}

Not applicable

\section{Conflict of interest}

There are no conflicts to declare

\section{References}

[1] M. Shah, D. Fawcett, S. Sharma, S. K. Tripathy and G. E. J. Poinern, Materials, 2015, 8, 7278-7308, doi: 10.3390/ma8115377.

[2] D. Pan, X. Zhang, G. Yang, Y. Shang, F. Su, Q. Hu, R. R. Patil, H, Liu, C. Liu and Z. Guo, Ind. Eng. Chem. Res., 2020, 59, 2037120381, doi: 10.1021/acs.iecr.0c04510.

[3] K. S. Siddiqi, A. Husen and R. A. Rao, J. Nanobiotech. 2018, 16, 14-18, doi: 10.1186/s12951-018- 0334-5.

[4] A. D. Dwivedi and K. Gopal, Physico. Eng. Aspects. 2010, 369, 27-33, doi: 10.1016/j.colsurfa.2010.07.020.

[5] R. A. Kołodziejczak and T. Jesionowski, Materials 2014, 7, 2833-2881, doi: 10.3390/ma7042833.

[6] J. Reichrath and K. Rass, Adv. Exp. Med. Bio.,2014, 810, 208213, doi: 10.1007/978-1-4939-0437-2_12.

[7] M. D. Newman, M. Stotland and J. I. Ellis, J. Amer. Acad. Dermato., 2009 ,61, 685-692, doi:10.1016/j.jaad.2009.02.051

[8] G. Khar, H. Padali, P. Moteriy and S. Chand, Arab. J. Sci. Eng. 2018, 43, 3393-3401, doi: 10.1007/s13369-017-2875-6.

[9] H. Liu, D. Yang, H. Yang, H. Zhang, W. Zhang, Y. Fang, Z. Lin, L. Tian and Z. Xi, J. Haz. Mater, 2013, 248, 478-486, doi: 10.1016/j.jhazmat.2013.01.046.

[10] M. Mirhosseini and F.B Firouzabadi, Inter. J. Dairy Technol., 2013, 66, 291-295, doi: 10.1111/1471-0307.12015.

[11] B. N. Singh, A. K. S. Rawat, A. H. Naqvi and B. R. Singh, PLoSOne, 2014, 9, 106937, doi: 10.1371/journal.pone.0106937.

[12] O. Yamamoto, Inter. J. Inog. Materials, 2001, 3, 643-646, doi: 10.1016/S1466-6049(01)00197-0.

[13] P. K. Stoimenov, R. L. Klinger, G. L. Marchin, K. J. Klabunde, Langmuir, 2002, 18, 6679-6686, doi: 10.1021/1a0202374.

[14] L. Reddy, M. Nisha, M. Joice, P. Shilpa, Pharma. Bio., 2014, 52, 1388-1397, doi: 10.3109/13880209.2014.893001.

[15] Y. Liu, L. He, A. Mustapha, H. Li, Q. Hu and M. Lin, J. Appl. Microbiol., 2009, 107, 1193-1201, doi: 10.1111/j.13652672.2009.04303.x.

[16] S. Ankanna, E. K. Elumalai and N. Savithramma, Dig. J. Nanomater. Biostruct., 2010, 5, 369-372.

[17] U. Klueh, V. Wagner, S. Kelly, A. Johnson and J.D. Brayers, .J. Bio. Mate. Res., 2000, 53, 621-631, doi: 10.1002/1097-4636 53:6<621:: AID JBM2>3.0.CO;2-Q.

[18] T. Dakal, A. Kumar, R. Majumdar and V. Yadav, Front. Microbial., 2016, 7, 1831-1837, doi: 10.3389/fmicb.2016.0183.

[19] D. Pan, F. Su, H. Liu, Y. Ma, R. Das, Q. Hu, C. Liu and Z. Guo, Chem. Rec., 2020, 20, 1314-1337, doi: 10.1002/tcr.202000079.

[20] A. Shakeel, M. Saifullah, S. Babu Lal, I. Saiqa, J. Radia. Res. Appl. Sci., 2016, 9, 1-7, doi:10.1016/j.jrras.2015.06.006.

[21] I. Sondi, S. B. Salopek, J. Colloid Inter. Sci., 2004, 275, $177-$ 182, doi: 10.1016/j.jcis.2004.02.012.

[22] S.G. Dastager, B. Sridhar, A. Dayanand and A. D. Shirley, 
Dig. J. Nanomater. Biostruct., 2010, 5, 447-451.

[23] P. Kamble, S. Suryawanshi, J. Jadhav and Y. Attar, J. Microbio. Methods, 2019, 159, 99-111, doi: 10.1016/j.mimet.2019.02.021.

[24] S. S. Suryawanshi, M. R. Rane, P. R. Kirsagar, P. P. Kamble and J. P. Jadhav, Inter. J. Pharm. Biolog. Sci., 2019, 9, 312-324, doi: 10.21276/ijpbs.2019.9.1.41.

[25] W. B. Williams, M. E. Cuvelier and C. Berset, Food Sci. Technol., 1995, 28, 25-30, doi: 10.1016/S0023-6438(95)80008.

[26] L.S.Yadav, S.Prathibha, K. Manjunath, M. Shivanna, T. Ramakrishnappa and N. Dhananjaya, J. Sci.: Adv. Mater. Devi., 2019, 3, 425-43, doi: 10.1016/j.jsamd.2019.03.001.

[27] I. A. Jafari, M. Ghane and S. Arastoo, Afr. J.Microbial. Res., 2011, 5, 5465-5473, doi: 10.5897/AJMR11.392.

[28] S. R. Prasad, M. N. Padvi, S.S. Suryawanshi,.Y.I. Shaikh, L. S. Chaudhary, A. P. Samant and N. R. Prasad, SN Appl.Sci., 2, 1-12, doi: 10.1007/s42452-020-2382-3.

[29] M.N. Padvi, N.G. Hiremath, S. R. D. Prasad, A. K. Nayak, R. A. Bohara, Y. Attrar, A. A. Ramteke and P. Sarvalkar, Macromole. Symp., 2020, 392, 1900172, doi: 10.1002/masy.201900172

[30] T. Dongale, N. Mullani, V. Patil, R. Tikke, P. Pawar, S. Mohite, A. Teli, A. Bagade, K. Pawar, K. Khot, S. Shinde, V. Patil, S. Vanalkar, A. Moholkar, P. Bhosale, P. Patil, R. Kamat, J. Nanosci. Nanotech., 2018, 18, 7758-7766, doi: 10.1166/jnn.2018.15540.

[31] P. B. Patil, S. B. Parit, P. P. Waifalkar, S. P. Patil, T. D. Dongale, S. C. Sahoo, P. Kollu, M. S. Nimbalkar, P. S. Patil, and A. D. Chougale, Mater. Lett., 2018, 223, 178-181, doi: 10.1016/j.matlet.2018.04.008.

[32] S. Delekar, K. More, A. Dhodamani, S. Patil, T. D. Dongale, K. Maity, N. Dalal, D. K. Panda, Mater. Characte., 2018, 139, 337-346, doi: 10.1016/j.matchar.2018.03.006.

[33] T. D. Dongale, N. D. Desai, K. V. Khot, C. K. Volos, P. N. Bhosale, R. K. Kamat, J. Nanoelec. Optoelec., 2018, 13, 68-75, doi: 10.1166/jno.2018.2297.
[34] S. D. Delekar, A. G. Dhodamani, K. V. More, T. D. Dongale, R. K. Kamat, S. F. A. Acquah, N. S. Dalal, and D. K. Panda, ACS Omega, 2018, 3, 2743-2756, doi: 10.1021/acsomega.7b01316.

[35] M. Rane, S. Suryawanshi, R. Patil, R. Patil, C. Aware, R. Jadhav, S. Gaikwad, P. Singh, S. Yadav, V. Bapat, R. Gurav, J. Jadhav, South African J. Bot, 2019, 124, 304-310, doi: 10.1016/j.sajb.2019.04.030.

[36] S.A. Jadhav, H.B. Garud, A.H. Patil, G.D. Patil, C.R. Patil, T.D. Dongale, P.S. Patil, Colloid and Interf. Sci. Comm., 2019, 30, 100181, doi: 10.1016/j.colcom.2019.100181.

[37] M.S. Akhtar, J. Panwar, Y. S. Yun, ACS Sustainable Chem. Eng., 2013, 1, 6, 591-602, doi: 10.1021/sc300118u.

[38] R. Kitture, S.Ghosh, P. A. More, K.Date, S. Gaware ,S. Datar, B. A. Chopade and S. N. Kale, J. Nanosci. Nanotechnol., 2015, 15, 4039-4045, doi: 10.1166/jnn.2015.10322.

[39] S. S. Chougule, S.T. Gurme, J.P. Jadhav, T.D. Dongale, and A.P. Tiwari, J. Plant Biochem. Biotechnol., 2020, 17, doi: 10.1007/s13562-020-00584-7.

[40] N.D. Thorat and J. Bauer, Appl. Surf. Science, 2020, 527, 1468093, doi: 10.1016/j.apsusc.2020.146809

[41] S.A. Gaware, K.A. Rokade and S.N. Kale, Journal of Drug Delivery Sci. and Techno., 2019, 49, 345-351, doi: 10.1016/j.jddst.2018.11.022.

[42] S. Gaware, K. Rokade, P. Bala, S. Kale, J Biomed. Mater. Res. Part A, 2019, 107A, 1582-1596, doi: 10.1002/jbm.a.36672. [43] A.V. Pawar, S. S. Kanapally, K. D. Kadam, S. L. Patil, V. S. Dongle, S. A. Jadhav, S. Kim, T. D. Dongale, J. Mater. Sci., 2019, 30, 11383-11394, doi: 10.1007/s10854-019-01487-7.

[44] S. Otari, R. Patil, N. Nadaf, S. Ghosh, S. Pawar, Mater. Lett., 2012, 72, 92-94, doi: 10.1016/j.matlet.2011.12.109.

Publisher's Note: Engineered Science Publisher remains neutral with regard to jurisdictional claims in published maps and institutional affiliations. 